\title{
An immunohistochemical, histological, and electron-microscopic study of the human periodontal ligament during orthodontic treatment
}

\author{
GIUSEPPE ANASTASI ${ }^{1}$, GIANCARLO CORDASCO ${ }^{2}$, GIOVANNI MATARESE ${ }^{2}$, GIUSEPPINA RIZZO ${ }^{1}$, \\ RICCARDO NUCERA ${ }^{2}$, MANUELA MAZZA ${ }^{2}$, ANGELA MILITI ${ }^{2}$, MARCO PORTELLI $^{2}$, \\ GIUSEPPINA CUTRONEO ${ }^{1}$ and ANGELO FAVALORO ${ }^{1}$
}

\begin{abstract}
Departments of ${ }^{1}$ Biomorphology and Biotechnologies, ${ }^{2}$ Odontostomatology, Policlinico Universitario 'G. Martino', University of Messina, Via Consolare Valeria, I-98125 Messina, Italy
\end{abstract}

Received March 2, 2007; Accepted April 3, 2007

\begin{abstract}
The periodontal ligament lies between the hard tissues of alveolar bone and cementum of teeth and serves to anchor the tooth to the alveolus and functions as a cushion between these hard tissues to migrate occlusal force during mastication. This tissue is always exposed to mechanical stress during mastication. When occlusal forces exceed the adaptive capacity of the periodontal ligament, the periodontal ligament tissue will be injured and then occlusal trauma will occur. The different modifications of periodontal ligament during load deformation can be monitored by analysis of the expression of different collagen types and fibronectin, with immunohistochemical techniques, and by morphological study of ligament, with light- and transmission electron-microscopic techniques. The use of continued and light orthodontic force generates a pressure of ligament with ejection of parodontal fluid externally and partial closing of vessels. On these basis we performed a study in order to evaluate periodontal ligament collagen types I and IV and the fibronectin modifications induced by application of a precalibrated orthodontic strength. We integrated these results, with light and transmission electron-microscopic observations, in order to evaluate the morphological modifications of periodontal tissue. Our observations showed that the type I collagen immunofluorescence staining is increased in the pressure side; in the tension side, it shows prior to treatment an increase, and after $72 \mathrm{~h}$ of treatment, a diminution of the staining pattern. Type IV collagen staining is reduced in both sides, but increased gradually after 7 days from treatment; finally, fibronectin staining pattern is gradually increased in
\end{abstract}

Correspondence to: Dr Angelo Favaloro, Dipartimento di Biomorfologia e Biotecnologie, Università degli Studi di Messina, Policlinico Universitario - Torre Biologica, Via C. Valeria, I-98125 Messina, Italy

E-mail: angelo.favaloro@unime.it

Key words: type I collagen, type IV collagen, fibronectin, periodontal ligament, orthodontic movement the pressure side and reduced in the tension side. In light and transmission electron-microscopic observations it is possible to show a reduction of vessels at $72 \mathrm{~h}$ from treatment, and an increase of vessels after 7 days from treatment. The Malassez's epithelial residues are decreased at $72 \mathrm{~h}$, while they are increased after 7 days from treatment. The modifications of immunofluorescence staining patterns of tested proteins revealed angiogenesis and reparative processes, and a thickening of fibrillar matrix as a defensive reply to mechanical stress. The modification of normal staining patterns of tested protein in our observations, could be determined by variation of scaffold geometry of periodontal ligament. The reduced movements of contraction and relaxation of periodontal ligament, due to orthodontic treatment, provoke a loss of mechanical stresses transmitted over ligament surface. Mechanical signals, therefore, could be integrated with other environmental signals and transduced into biochemical signals through force-dependent changes in scaffold geometry. Physical forces of gravity, hemodynamic stresses, and movement play a critical role in tissues, since the cells use tensegrity architecture for their structural organization.

\section{Introduction}

The periodontal ligament is a membrane-like connective tissue surrounding the root of a tooth. It lies between the hard tissues of alveolar bone and cementum of teeth and serves to anchor the tooth to the alveolus and functions as a cushion between these hard tissues to migrate occlusal force during mastication. This tissue also plays key roles in supporting the tooth in the bone socket of the jaw and also in maintaining homeostasis of the surrounding tissues, such as alveolar bone and cementum (1).

Many histological studies, using light- and electronmicroscopy, have showed that the integrity of the tissue is lost as a function of age in human as well as in experimental animals (2-4). The periodontal ligament is always exposed to mechanical stress during mastication. When occlusal forces exceed the adaptive capacity of the periodontal ligament, the periodontal ligament tissue will be injured and occlusal trauma will occur. 
Histological and clinical studies have clearly indicated occlusal trauma in alveolar bone loss of crestal height $(5,6)$. It has been shown that mechanical tension force, using a Flexer strain unit apparatus, significantly increased IL- $ß 1$, prostaglandin E2 $(7,8)$, and plasminogen activator activity (9) in human periodontal ligament derived fibroblast cells.

The clinical relevance of parodontal tissues clearly exceeds the current knowledge of their ultrastructure. Regenerative and reparative processes of root cementum and connective-tissue attachment on hard tissues generate greater interest than the ultrastructure and structural biology of these tissues, and many recent studies have focused on cementogenesis $(10,11)$ or on the metabolism of periodontal cells $(12,13)$.

The cemental insertion of the periodontal ligament deserves particular attention because of the growing importance of guided tissue-regeneration techniques and the dependence of the development of new connective tissue attachments from the bioactivity of their tissues (14-16).

In addition, load deformation and stress strain curves for the periodontal ligament can be obtained by loading a transverse section of a tooth axially in vitro (16-18). In this way, the studies of the effects of various factors such as occlusal conditions $(19)$, different root levels $(18,20)$ on the biomechanical properties of the ligament have suggested that the load deformation and stress strain curves are determined largely by the geometrical arrangement and the nature of the periodontal fibres (18).

The different modifications of periodontal ligament during load deformation can be monitored by analysis of the expression of different collagen types, with immunohistochemical techniques, and by morphological study of ligament, with light- and transmission electron-microscopic techniques. Collagen type I, a heterotrimer consisting of two $\alpha 1$ and one $\alpha 2$ (21) subunits, is the major collagen produced by prechondrogenic mesenchymal cells. As these cells differentiate into cartilage-producing cells they terminate collagen type I synthesis and initiate the synthesis of cartilage specific collagens such as types II, IX and XI (21). However, during chondrocyte culture and under pathological conditions such as osteoarthritis collagen type I appears to be re-expressed (22-25).

Collagen type IV is one of the major constituents of the basement membrane, and is composed of a central triplehelical region (TH domain), an amino-terminal triple-helix domain (7S domain) and a carboxy-terminal globular noncollagenous domain (NC1 domain) (26). Collagen type IV, also, is the major component of vascular basement membrane and it plays a crucial role in angiogenesis (27). It was demonstrated that the remodeling of vascular basement membrane can provide crucial angiogenic and anti-angiogenic molecules to control the formation of new capillaries (28).

Fibronectin is one the first extracellular matrix proteins produced by odontoblast and osteoblasts (29-31). Fibronectin is composed of two similar polypeptide chains whose subunits chains are linked by disulfide bonds $(31,32)$. It is a multidomain protein containing a large number of small structural domains (31). In addition this protein has been suggested to play a key role in the interaction of the implant surface and surrounding matrix (29-31).
It is known that collagen and fibronectin molecules play a key role in tissue's remodelling processes, following orthodontic movement (33). In particular, the collagen type I is quantitatively most present $(78.06 \%)$ in periodontal ligament, forms compact fibers anchored to cement and to alveolar bone making the periodontal ligament to oppose masticatory forces. The collagen type IV is localized in basal membranes of vessels. Fibronectin is essential to the periodontal ligament fibroblast migration forming proteic system of matrix. Besides, fibronectin plays a key role in degradation of matrix during periodontitis in human teeth.

Some ultrastructural and analytical research has been done on periodontal tissues, however, the published findings vary widely. Most recent studies converge on animal models (34-36) but reveal that a wide dissimilarity exists among equivalent tissues in different species, so that data obtained from animal models are often impossible to extend to humans. Ultrastructural studies on human tissues are still insufficient $(37,38)$.

On these basis we performed a study on modification induced by application of a precalibrated and constant orthodontic strength of periodontal ligament. The percentage of adult patients who seek orthodontic treatment has increased significantly in recent years. The orthodontic treatment consist on principle of a continued application of pressure on the tooth, causing displacement with remodelling process of alveolar bone.

The tooth moves in the interior of the bone dragging the attach periodontal system together with alveolar processes. It is known that orthodontic movement consist of pressuretension mechanism; the tooth movement is produced by modification of cellular activities stimulated through chemical messengers, which are generated by variations of blood flux in periodontal ligament.

The use of continued and light orthodontic force generates a pressure on the ligament with ejection of the parodontal fluid externally and partial closing of vessels (39). Alteration of blood flux and variation of oxygen tension influences the cellular activity and it is possible to note an increase of cAMP, important for cellular differentiation, and PG-E that has cellular specific activity (40).

In the periodontal ligament of some teeth, small patches of hyalinization were found at the pressure side, mostly located buccally or lingually of the mesiodistal plane, whereas large areas showed necrotic tissue. Therefore, the hyalinization limits tooth movement, but there is no relationship with the force level.

The aim of this study was to evalue periodontal ligament collagen types I and IV and the fibronectin modifications induced by application of a precalibrated and constant orthodontic strength at different stages of treatment. We integrated these results, with light and transmission electronmicroscopic observations, in order to evaluate the morphological modifications of periodontal tissue.

\section{Materials and methods}

Tissue preparation. For this study we utilized a coilspring NiTi 50 gr in vivo human samples of 20 premolars, 10 maxillaries and 10 mandibulars, of 10 patients aged from 13 
to 18 years, subjected to orthodontic treatment. These teeth were extracted at 3 and 72 h, 7 and 14 days from application of force, respectively.

The extraction of the periodontal ligament scared the radicular surface on the pressure and tension side. The results were compared with periodontal ligament samples of the normal homologous teeth (control).

Immunohistochemistry. The periodontal ligament samples were fixed in $3 \%$ paraformaldehyde in a $0.2 \mathrm{M}$ phosphate buffer at $\mathrm{pH}$ 7.4. After numerous rinses in $0.2 \mathrm{M}$ phosphate buffer and saline phosphate buffer (PBS), they were infiltrated with $12 \%$ and $18 \%$ saccharose, then frozen in liquid nitrogen and sliced on a cryostat, following the protocol used to carry out indirect immunofluorescence.

The sections, about $20 \mu \mathrm{m}$ thick, were cut on a cryostat and collected on glass coated with $0.5 \%$ gelatin and $0.005 \%$ chromium potassium sulfate. To block non-specific sites and render the membranes permeable, the sections were preincubated with $1 \%$ BSA and $0.3 \%$ Triton $\mathrm{X}-100$ at room temperature for $15 \mathrm{~min}$. Finally, the sections were incubated with primary antibody.

The following primary antibodies were used: anticollagen I (Sigma Chemicals, St. Louis, MO) diluted 1:100, anti-collagen IV (Sigma Chemicals) diluted 1:100 and antifibronectin (Sigma Chemicals) diluted 1:100. In all reactions, TRITC-conjugated IgG goat anti-mouse was used as first fluorochrome, diluted at 1:100, applied after incubation with the primary antibody.

Sections were then observed and photographed using a Zeiss LSM 510 confocal microscope, equipped with an Argon laser (458 and $488 \mathrm{~nm}$ ) and two HeNe lasers (543 and $633 \mathrm{~nm}$ ). All images were digitized at a resolution of 8 bits into an array of 2048x2048 pixels. Optical sections of fluorescence specimens were obtained using $\mathrm{HeNe}$ laser (543 nm) and Argon laser (458 nm) at a 1-min $2 \mathrm{sec}$ scanning speed with up to 8 . Thick sections $(1.50 \mu \mathrm{m})$ were obtained using a pinhole of 250 .

Contrast and brightness were established by examining the most brightly labeled pixels and choosing a setting that allowed clear visualization of structural details, while keeping the highest pixel intensities near 200. The same settings were used for all images obtained from other samples that had been processed in parallel. The images presented were obtained using a function of the software provided by the manufacturer of the microscope.

The function, called 'display-profile', allowed us to show the intensity profile across the image along a freely selectable line. The intensity curves are shown in a graph below the scanned image.

The graphics were obtained analyzing fluorescence intensity data and elaborating them with Microsoft Excel. Digital images were cropped and figures prepared using Adobe Photoshop 7.0.

Light microscopy. The specimens were fixed overnight in $2.5 \%$ glutaraldehyde plus $4 \%$ paraformaldehyde in $0.1 \mathrm{M}$ sodium cacodylate buffer at $4{ }^{\circ} \mathrm{C}$, dehydrated in ethanol and infiltrated with Technovit 9100.

Semithin sections $(1 \mu \mathrm{m})$ were cut with an ultramicrotome (LKB Ultrotome V) and were stained with toluidine blue- pironine for $5 \mathrm{~min}$, then the sections were examined and photographed with an Olympus BH-2 microscope.

Transmission electron microscopy. For electron microscopy, the periodontal ligament was exposed, and prefixed in $4 \%$ glutaraldehyde fixative buffered by phosphate at $\mathrm{pH}$ 7.2-7.4. The samples were then tied to an applicator stick, removed, and placed in the larger volume of the same fixative at $4^{\circ} \mathrm{C}$ for $2 \mathrm{~h}$ more. We made every effort not to damage the periodontal ligament.

After prefixation the samples were fixed in $1 \% \mathrm{OsO}_{4}$ buffered to $\mathrm{pH} 7.2$ with $0.1 \mathrm{M}$ phosphate buffer containing $0.54 \%$ glucose. The fragments were then dehydrated in ethanol and embebbed in Durcupan. Semithin sections were cut and evaluated, by light microscopy in order to better define the field of observation. Ultrathin sections, obtained using a microtome LKB Bromma 2088 Ultrotome V and mounted on 200- to 300-mesh copper grids, were stained, according to Reynolds (41) using uranyl acetate in $70 \%$ ethanol and lead citrate solutions, and examined with a Phillips CM 10 transmission electron-microscope.

\section{Results}

Immunohistochemistry. Immunofluorescence reactions were performed in order to verify the immunostaining patterns of type I collagen, type IV collagen and fibronectin, in human periodontal ligament both normal and after 3 and 72 h, 7 and 14 days from orthodontic treatment. The sections were analyzed using a stack of 16 sections ( $0.8 \mu \mathrm{m}$ of scan step), and carried out on $20 \mu \mathrm{m}$ thick cryosections of periodontal ligament.

The control reactions showed that type I collagen is uniformly distributed and that vessels are clearly detectable (Fig. 1). After $3 \mathrm{~h}$ from treatment, type I collagen staining was increased in the tension and pressure side (Fig. 2a and b). After $72 \mathrm{~h}$ from treatment, in both sides the protein staining was gradually increased (Fig. 2c and d). At 7 days, type I collagen staining pattern, was severely reduced in the tension side (Fig. 2e), while, in the pressure side the immunofluorescence of this protein showed the same values as the samples obtained at $72 \mathrm{~h}$ from treatment (Fig. 2f). After 14 days from orthodontic treatment, the type I collagen staining pattern, in the tension side, continues to increase (Fig. 2g). In the pressure side, immunofluorescence of this protein, was severely reduced (Fig. 2 h).

Immunofluorescence analysis of type IV collagen, compared with control reaction (Fig. 3) showed a gradual decrease of protein staining at 3 and $72 \mathrm{~h}$ after the treatment, in the tension (Fig. 4a and c) and in the pressure (Fig. 4b and d) sides. After 7 days, type IV collagen staining pattern, both the tension (Fig. 4e) and pressure (Fig. 4f) sides, showed a light increase of immunofluorescence. This staining pattern increase, became more evident at 14 days from treatment, in both sides (Fig. 4g and h).

The fibronectin staining pattern, compared with control reaction (Fig. 5) was gradually increased, in the pressure side at the various stages of treatment (Fig. $6 b, d, f$ and $h$ ). In the tension side, the immunofluorescence staining of fibronectin was decreased (Fig. 6a, c and e), until it was almost absent at 14 days (Fig. 6h). 


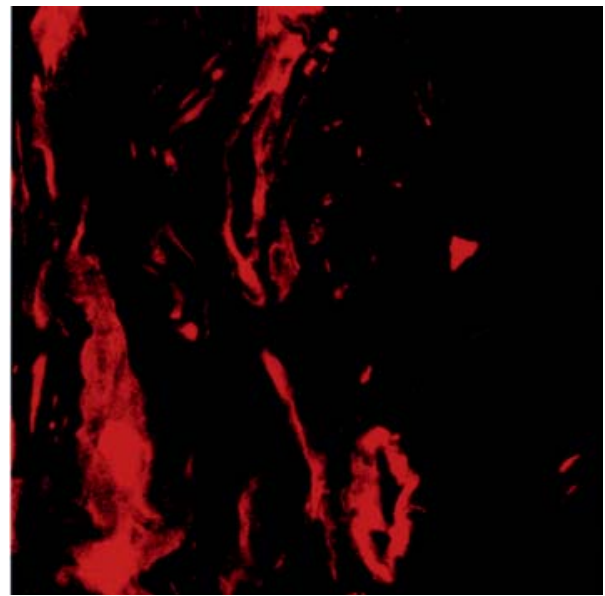

Figure 1. Confocal scanning laser microscopic observation of control periodontal ligament immunolabeled with type I collagen. All portions, including vessels, of periodontal ligament showed a normal distribution.

\section{Tension}
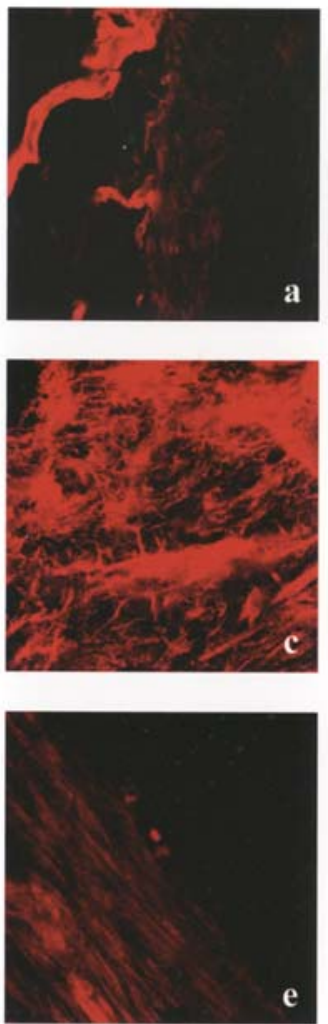

g
Pressure
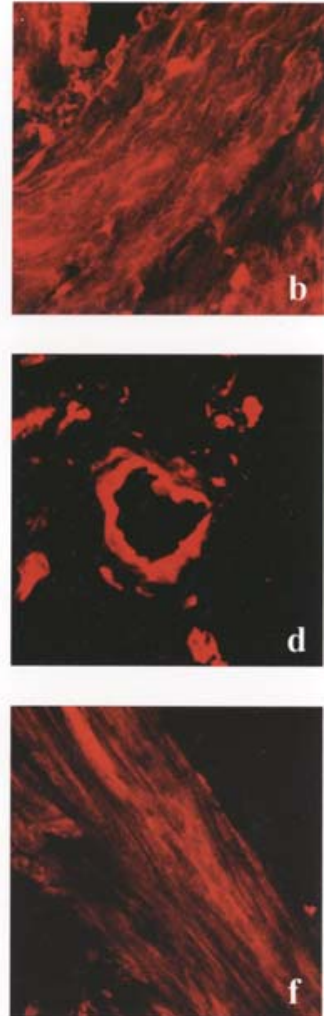

f
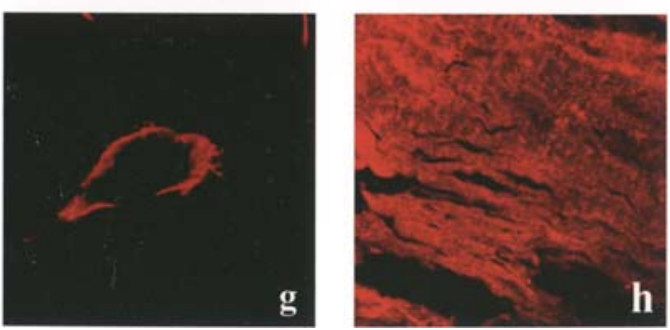

Figure 2. Confocal scanning laser microscopic observation of periodontal ligament immunolabeled with type I collagen obtained after $3 \mathrm{~h}(\mathrm{a}$ and b), $72 \mathrm{~h}$ (c and d), 7 days (e and f), and 14 days ( $g$ and h) from treatment. The staining pattern of this protein showed an increase, in respect to control, in the tension and pressure side, until $72 \mathrm{~h}$. After this stage the type I collagen staining decreased in the tension side, and maintained the same values in the pressure side.

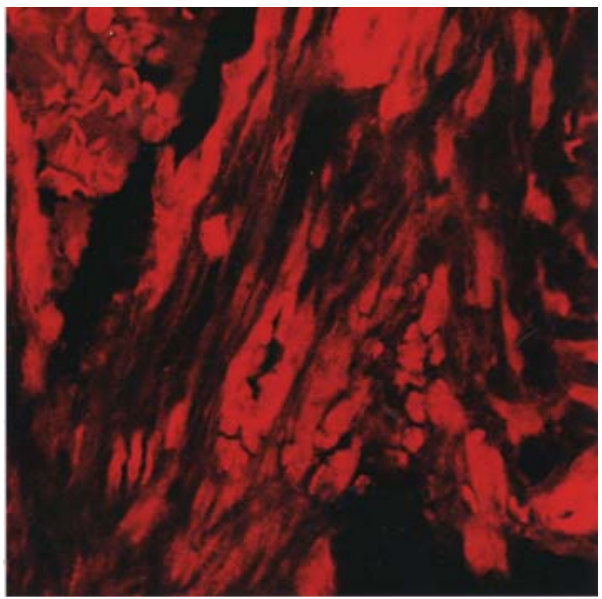

Figure 3. Confocal scanning laser microscopic observation of control periodontal ligament immunolabeled with type IV collagen. All portions, including vessels, of periodontal ligament showed a normal distribution.

$3 \mathbf{h}$
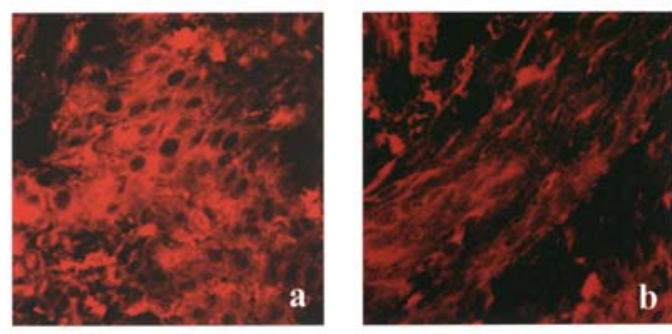

$72 \mathrm{~h}$
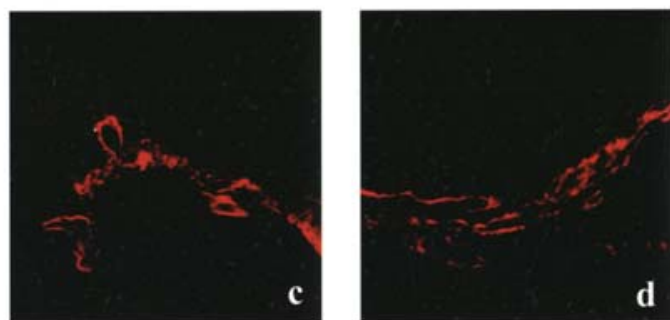

7 days
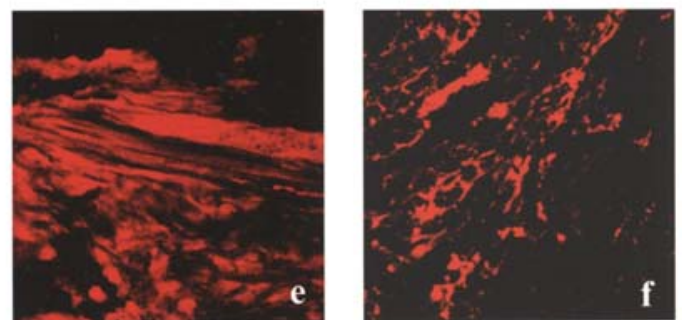

14 days
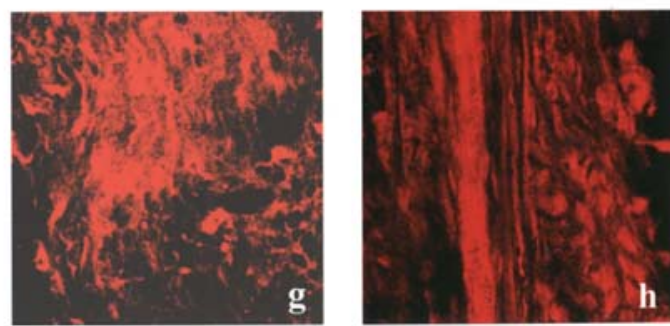

Figure 4. Confocal scanning laser microscopic observation of periodontal ligament immunolabeled with type IV collagen obtained after $3 \mathrm{~h}$ ( $\mathrm{a}$ and $\mathrm{b}$ ), $72 \mathrm{~h}$ (c and d), 7 days (e and f), and 14 days ( $\mathrm{g}$ and $\mathrm{h}$ ) from treatment. The staining pattern of type IV collagen gradually decreased until $72 \mathrm{~h}$. After 7 days the immunofluorescence increased until 14 days. 


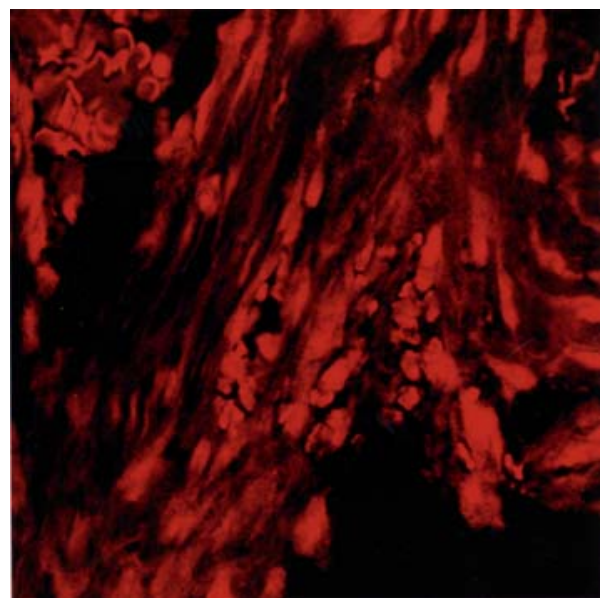

Figure 5. Confocal scanning laser microscopic observation of control periodontal ligament immunolabeled with fibronectin. All portions of periodontal ligament showed a normal distribution.

\section{Tension}
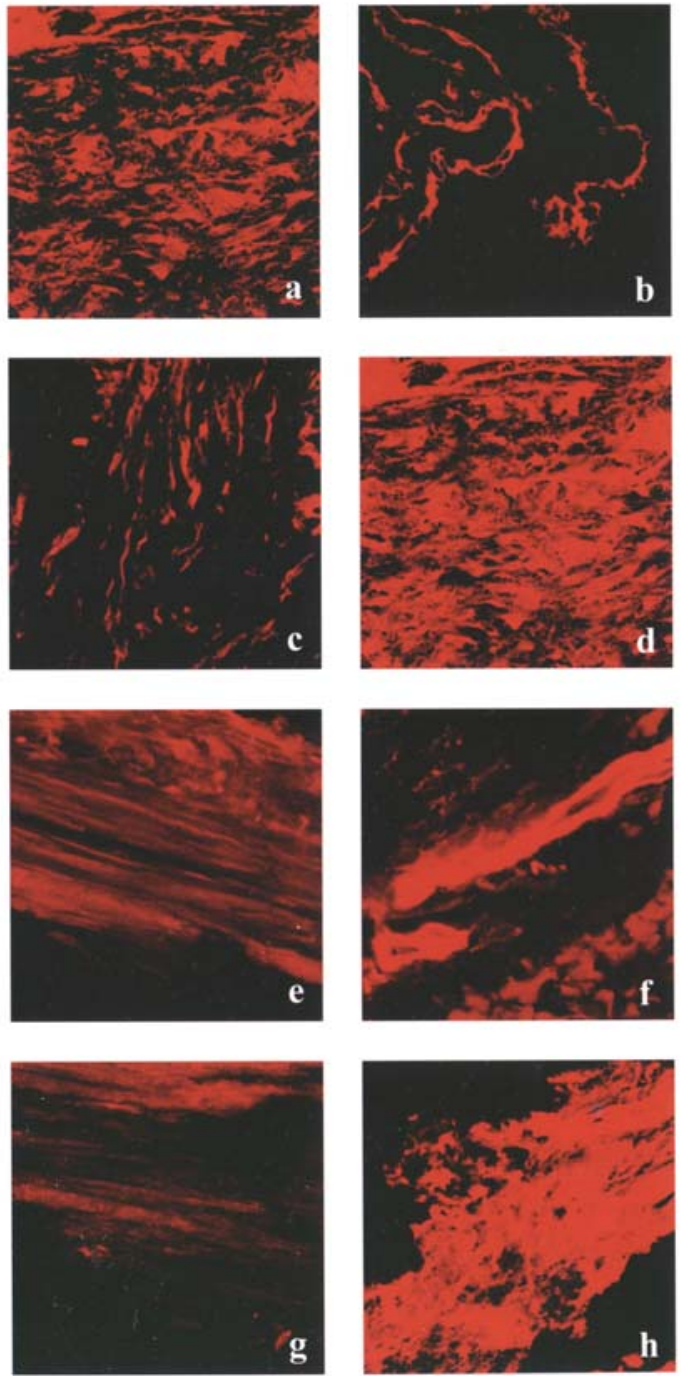

Figure 6. Confocal scanning laser microscopic observation of periodontal ligament immunolabeled with fibronectin obtained after $3 \mathrm{~h}$ (a and b), $72 \mathrm{~h}$ (c and d), 7 days (e and f), and 14 days ( $\mathrm{g}$ and $\mathrm{h}$ ) from treatment. The fibronectin staining pattern increased in the pressure side, while, in the tension side decreased until 14 days from treatment.
In addition, in order to investigate the presence of the tested protein staining we applied the software 'display profile' to all reactions. This further analysis, screening the intensity profile across the image along a freely selectable line, confirmed the type IV collagen staining. In particular, this protein, compared with control reaction (Fig. 7a), showed fluorescence intensity values included between 30 and 130, at $3 \mathrm{~h}$ from treatment (Fig. 7b). These fluorescence peaks, at $72 \mathrm{~h}$, were severely reduced (Fig. 7c), until the fluorescence was almost absent at 7 days (Fig. 7d), with fluorescence values at 0 to 80 . After 14 days from treatment, the type IV collagen showed intensity peaks which return to almost normal with values up to 180 (Fig. 7e).

The results obtained on type I collagen and fibronectin stainings, analyzed using software 'display profile', reflected the results obtained with the simple observations of tested proteins (data not shown).

The results obtained with confocal laser scanning microscopy were used in the graphics (Fig. 8) which indicate the behaviour of the tested protein. In Fig. 8a, we show the behaviour of type I collagen in control reaction (blue line), in the pressure side (red line), and in the tension side (yellow line). The graphics show that in the pressure side the staining pattern of type I collagen increases gradually until 14 days from treatment; instead, in the tension side, the yellow line shows that the staining pattern of type I collagen increases until $72 \mathrm{~h}$. After this stage, the immunostaining of protein decreases progressively.

In Fig. 8b, we show the process of fluorescence for type IV collagen. In both sides the staining pattern of this protein decreases gradually until 7 days from treatment. After this period, the immunofluorescence of type IV collagen increases. Finally, Fig. 8c, shows an increase of staining pattern of fibronectin until $72 \mathrm{~h}$, both in the tension and in the pressure side. After $72 \mathrm{~h}$, the immunofluorescence of this protein continues to increase in the pressure side, while decreases in the tension side.

Light microscopy. Morphological analysis of control periodontal ligament (Fig. 9a) showed the presence of numerous collagen fibrils thickened in defined bundles. The fibroblasts are tapering and possess thin cytoplasmic extensions; their axis is parallel with collagen fibrils. It is possible to see the vascular component and some Malassez's epithelial residue. At $3 \mathrm{~h}$ from treatment (Fig. 9b), light microscopic observation showed a reduced vascular component; the fibroblast and collagen components are thinner and less numerous; the same behaviour is shown for Malassez's epithelial residues.

After $72 \mathrm{~h}$ from treatment (Fig. 9c), the periodontal ligament showed severe damage, with almost no collagen fibrils and few vessels. Besides, the fibroblasts showed their axis not parallel with collagen fibrils, demonstrating a disorganization of periodontal ligament structure.

At 7 days (Fig. 9d), the fibroblast component has numerous vessels and Malassez's epithelial residues; moreover, the structure becomes again more organized. Finally, after 14 days from treatment (Fig. 9e), the vascular component is most developed and fibroblasts are at the peak level. Malassez's epithelial residues are numerically increased and their volume is at the peak of development. 


\section{Control}

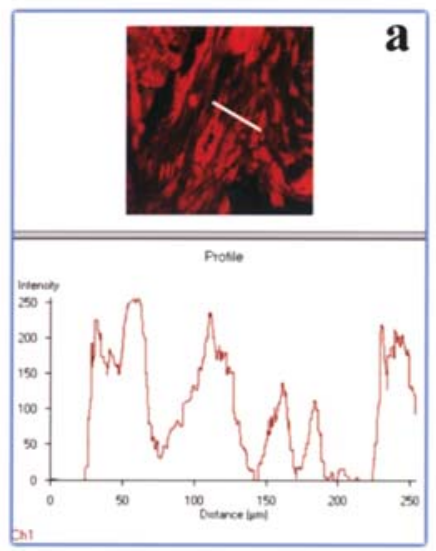

3 h.

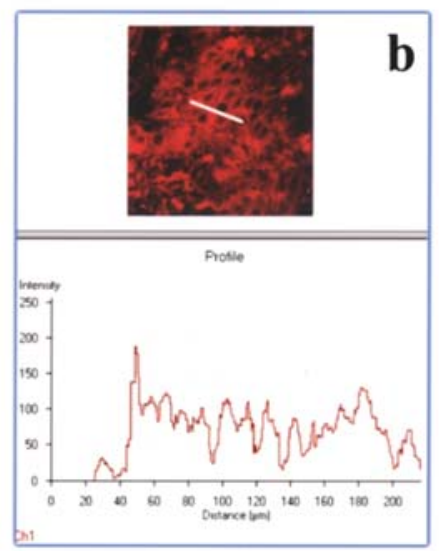

$72 \mathrm{~h}$.

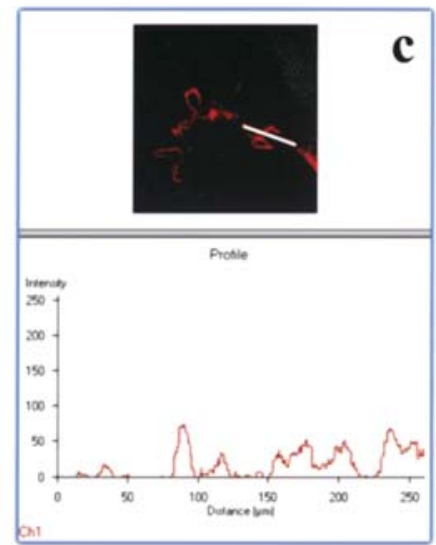

7 days

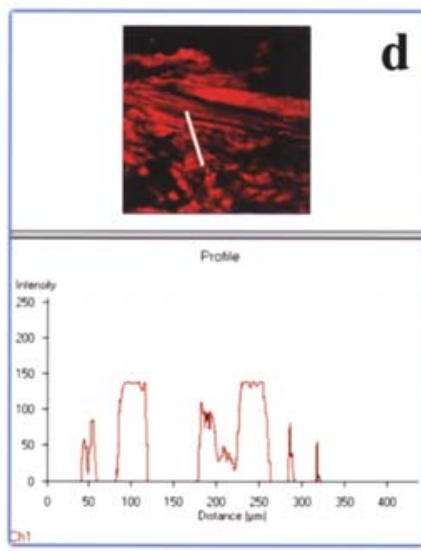

14 days

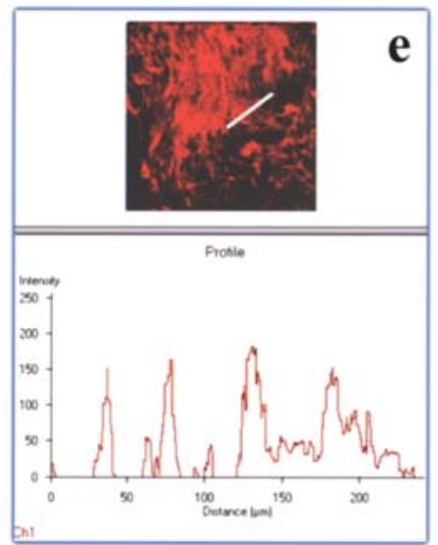

Figure 7. Display profile of the periodontal ligament immunolabeled with type IV collagen. The fluorescence peaks, compared with control reaction (a) revealed that this protein staining, in the tension side, decreased at $3 \mathrm{~h}(\mathrm{~b})$ and $72 \mathrm{~h}$ (c) after treatment, and increased gradually, at day 7 (d) and day 14 (e).

Transmission electron microscopy. Our observations, carried out with transmission electron-microscope, revealed that, in control samples, the fibroblasts have a normal cytoplasm proportioned with nucleus (Fig. 10a); the collagen fibrils are numerous and organized in parallel bands (Fig. 10b). At 3 $\mathrm{h}$ from orthodontic treatment, the ultrastructure of fibroblasts is less abundant while the nucleus shows normal activity, the morphology is roundish (Fig. 10c); the collagen component becomes less abundant and it is possible to note only a few fibrils (Fig. 10d).

After $72 \mathrm{~h}$, the fibroblasts showed an ultrastructural disorganization with wider nucleus and a sparse cytoplasm, losing the proportion between nucleus and cytoplasm (Fig. 10e); collagen fibrils are severely reduced, because the fibroblasts were also able to phagocyte the collagen fibrils (Fig. 10f).

At 7 days after treatment, the cytoplasm of fibroblasts returned to an abundant and most developed state (Fig. 10g); additionally, the macrophages frequently indicated reparative processes during mechanical stress (Fig. 10h).

After 14 days, the cytoplasm of fibroblasts was most abundant (data not shown), indicating a remodelling process of periodontal ligament. The vascular component increased considerably, indicating a further increase of neoangiogenesis (Fig. 10i). The Malassez's epithelial residues were most numerous and showed a large volume (Fig. 101).

\section{Discussion}

In this work we analyzed, with confocal laser scanning microscope, the periodontal ligament collagen types I and IV and the fibronectin modification on subjects during application of a precalibrated and constant orthodontic strength. Our observations showed that: a) type I collagen immunofluorescence staining is increased in the pressure side. In the tension side, it shows prior to treatment an increase and after $72 \mathrm{~h}$ of treatment, a diminution of staining pattern; b) type IV collagen staining is reduced in both sides, but increased gradually after 7 days from treatment; c) finally, fibronectin staining pattern is gradually increased in the pressure side and reduced in the tension side; d) in light and transmission electron-microscopic observations it is possible to show a reduction of vessels at $72 \mathrm{~h}$ from treatment, and an increase 

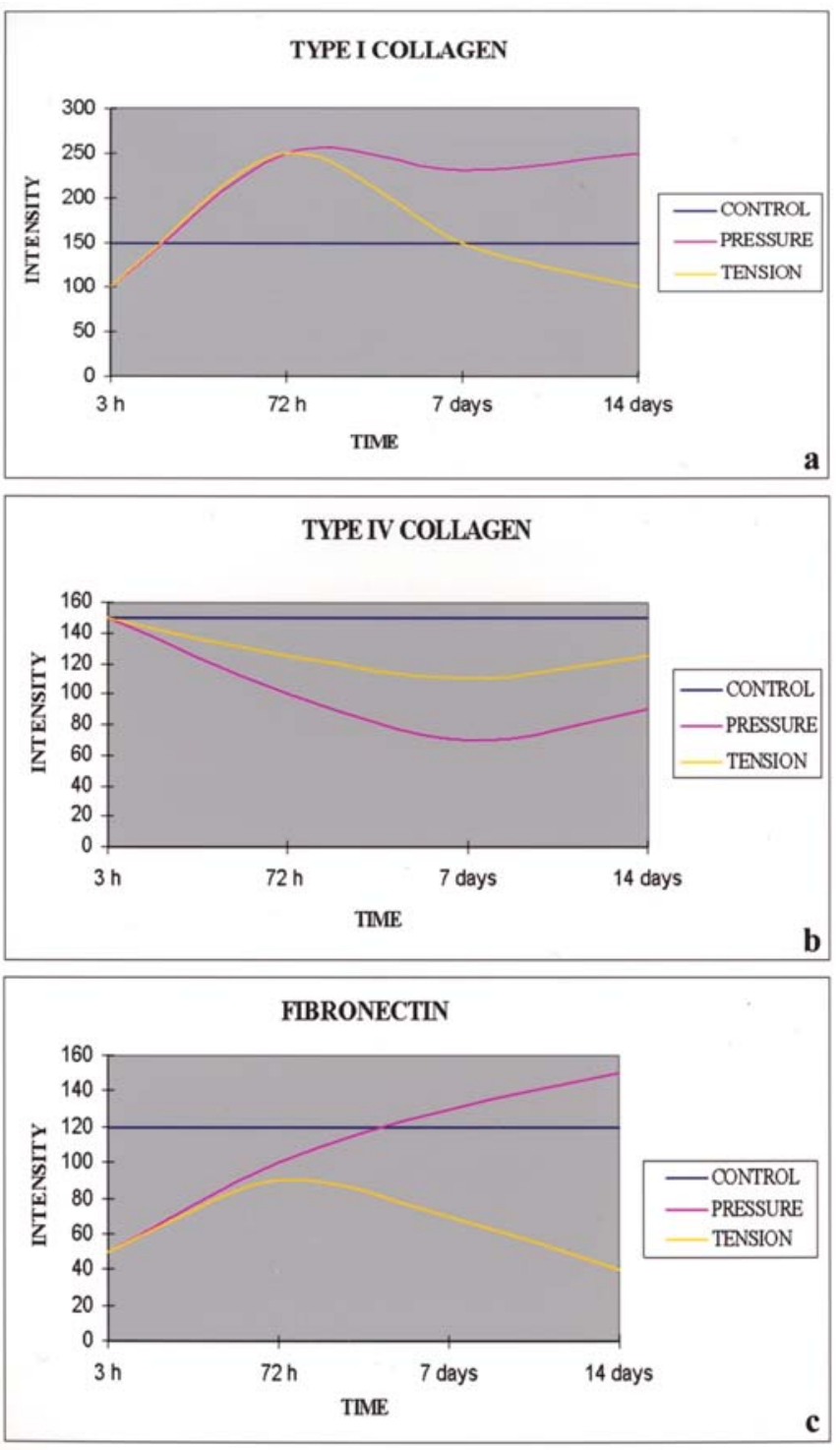

Figure 8 . The graphics based on the results obtained with confocal laser scanning microscopy with type I collagen (a), type IV collagen (b), and fibronectin $(c)$.

of vessels after 7 days from treatment. The Malassez's epithelial residues are decreased at $72 \mathrm{~h}$, while they are increased after 7 days from treatment.

Possible changes in the fiber configuration of the periodontal ligament in relation to its load-deformation curve have been previously investigated (42-44). The mechanical response of a soft tissue to external stress is non-linear $(45,46)$. On minor straining, the tissues present little resistance to elongation, which translates graphically into a relatively flat segment to the load-displacement curve that is also referred to as the 'toe'. After maximum uncoiling and stretching, the fibers begin to break. At this stage, the curve becomes ragged until final rupture occurs (47).

An essential element in mechanical response is the ground substance, glycoproteins, glycosamino-glycans, glycolipids, and proteoglycans immersed in water (48). Most of these macromolecules tend to swell when they are encased in a collagen matrix. They will also exhibit destructive behavior due to their resistance to flow under shear loading (49).

\section{Control}
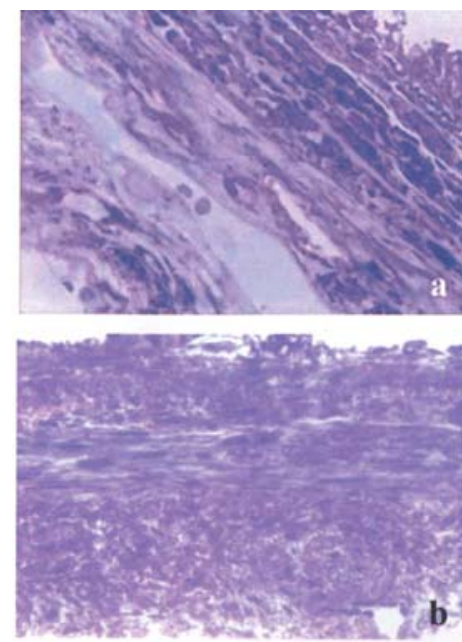

$72 \mathrm{~h}$
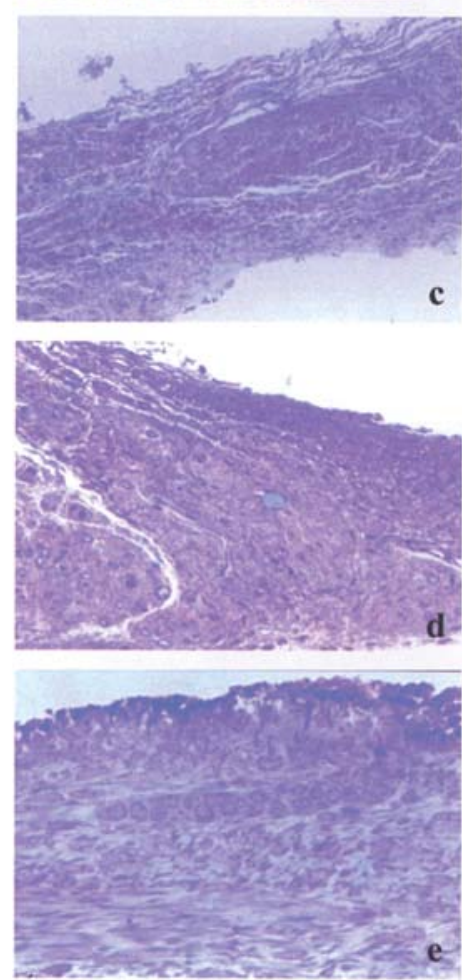

Figure 9. Light microscopic samples of periodontal ligament coloured with toluidine blue and obtained at various stages of treatment. Compared with control sample (a), at $3 \mathrm{~h}$ from treatment, vascular component, fibroblasts, and Malassez's epithelial residues are reduced (b). After $72 \mathrm{~h}$, the periodontal ligament showed a decrease of collagen fibrils and vessels. Besides, it is possible to note a disorganization of collagen fibrils (c). At 7 days from treatment, the fibroblast component, vessels, and Malassez's epithelial residues increased and the structure becomes again more organized (d). After 14 days, vascular component and fibroblasts again increased and Malassez's epithelial residues are at the peak of development (e).

Another important element in tooth support is the vasculature. The participation of the periodontal blood vessels in tooth support has been showed $(42,50)$, but there are insufficient data on the mechanisms and their relative importance (51). Besides, periodontal ligament also contains elastic fibers, which provide for regulatory function of the blood supply (52). Their role in the mechanical properties of periodontal ligament has not yet been clarified, but they may contribute to the overall elasticity of the tissue. 


\section{Control}
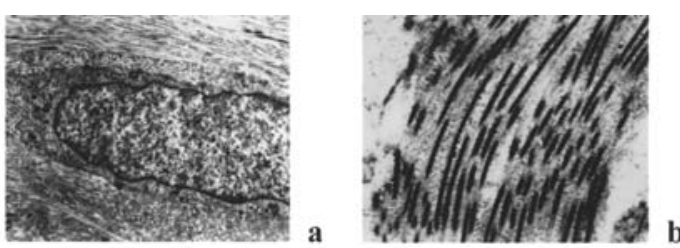

$3 \mathbf{h}$

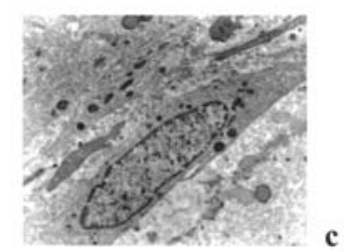

$72 \mathrm{~h}$

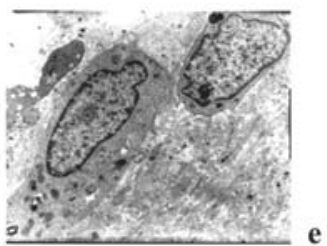

,
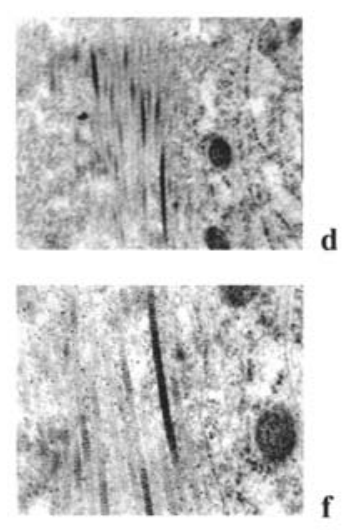

7 days
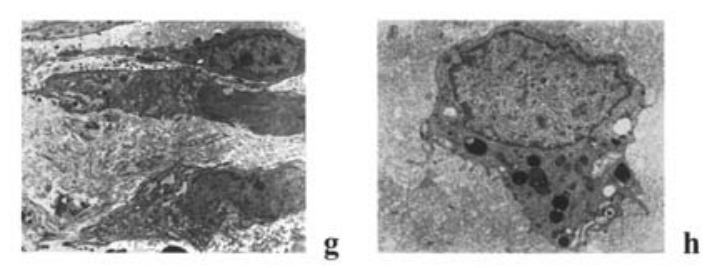

14 days
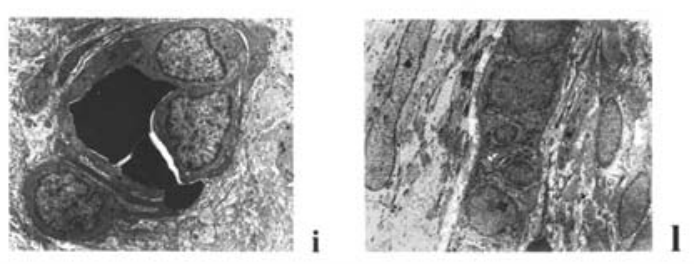

Figure 10. Transmission electron-microscopic images obtained at various stages of treatment. In control observations, the fibroblasts showed a normal cytoplasm proportioned with nucleus (a), and collagen fibrils are organized in parallel bands (b). After $3 \mathrm{~h}$, the ultrastructure of fibroblasts is less abundant and their morphology is almost roundish (c); it is possible to note few collagen fibrils (d). At $72 \mathrm{~h}$ from treatment, the nucleus of fibroblast is wider and cytoplasm sparse (e); collagen fibrils are severely reduced (f). After 7 days, the cytoplasm of fibroblasts become abundant $(\mathrm{g})$; macrophages are present indicating reparative processes (h). At 14 days from treatment, the vascular component increases considerably (i), and there is a massive presence of Malassez's epithelial residues (1).

Extracellular matrix also plays an important role in the regulation of cell dynamics and cell behavior by providing extracellular signals via receptor mediated signaling. Type I collagen is the major component of the ECM which provides tensile strength and support, as well as modulates various cellular functions. The mechanical stimulation of periodontal ligament alters type I collagen, tropoelastin and fibronectin production and these cells are differentially responsive to varying levels of mechanical stress (53).

Collagen is the main structural protein in vertebrates. It plays an essential role in providing a scaffold for cellular support and thereby affecting cell attachment, migration, proliferation, differentiation, and survival. As such, it also plays an important role in numerous approaches to engineer human tissue for medical applications related to tissue, bone, and skin repair and reconstruction.
On the basis of our results, increase of collagen type I immunostaining on the pressure side can be hypothesized for use in the establishment of a thickening of fibrillar matrix as defensive reply to mechanical stress. In our opinion, this behaviour can play a key role in the establishment of a hyalinization process. There is evidence showing an association between type I collagen and growth factors during the process of wound healing. An application of basic fibroblast growth factors (bFGF) to type I collagen sponge enhanced dermal wound healing (54).

The progressive decrease of collagen type IV immunostaining, in all samples, can indicate a loss a vascular component. This protein is localized, mainly, in perivessel zones. We are able to confirm that on the side of pressure there is indeed hyalinization. After 7 days from application of force, collagen type IV shows an increased staining pattern. This behaviour can indicate an angiogenesis process. In fact an induction of angiogenesis was detected after embedding collagen sponge soaked with several growth factors including IGF-I in the mouse subcutaneous tissue (55).

Angiogenesis is a complex process that involves ECM remodelling, migration, proliferation, and the functional maturation of mature blood vessels $(56,57)$. Type IV collagen plays a crucial role in angiogenesis (27). Vascular basement membrane constitute an important component of blood vessels (58). Remodelling of vascular basement membrane can provide crucial angiogenic and anti-angiogenic molecules to control the formation of new capillaries $(59,60)$.

The increase of fibronectin immunostaining on the side of pressure and the positive trend on the side of tension could be relative to reparative processes, as occur in the cicatrisation skin process. The fibronectin can promote the growth of periodontal ligament cells and may play different effects on the attachment and proliferation of periodontal ligament cells. It could be hypothesized that the increase of collagen type I and fibronectin immunostaining on pressure side could indicate that the force could determine an increase of metabolic activity in the periodontal ligament.

Our light and transmission electron-microscopic observations confirm these hypothesis. The increase of the Malassez's epithelial residues indicates the proliferative capacity due to inflammatory processes of periodontal ligament; the increase of vessels indicates an angiogenic process that involves during application forces.

The modification of normal staining patterns of tested protein in our observations, could be determined by variation of scaffold geometry of periodontal ligament. The reduced movements of contraction and relaxation of periodontal ligament, due to orthodontic treatment, provoke a loss of mechanical stresses transmitted over the ligament surface. Mechanical signals, therefore, could be integrated with other environmental signals and transduced into a biochemical signal through force-dependent changes in scaffold geometry. Physical forces of gravity, hemodynamic stresses, and movement play critical roles in tissues, since the cells use tensegrity architecture for their structural organization (61). Tensegrity is a neologism utilized to indicate the balance among tension and compression that causes some objects to maintain their structural integrity under tension. More generally, the structural shape of a tensegret is guaranteed by 
interaction between a set of members in tension and a set of a member in compression.

Our results, obtained on human samples, not only make clear the behaviour and function of the periodontal ligament proteins during orthodontic treatment, but also open a new research line in order to clarify the interaction of these proteins in the context of periodontal ligament. Similar studies could be performed in human periodontal ligament obtained from patients of different ranges of ages and of male and female subjects. It is demonstrated that increased estrogen levels were related to an increase in anterior cruciate ligament laxity (62) and they stimulated types I and III collagen synthesis at the mRNA level (63).

It would be intriguing also to integrate this study with observation of integrin staining because the constituents of vascular basement membrane contain binding sites for cell surface integrins for cellular attachment (64). Integrins modulate changes in cell shape and signal-transduction events in the absence of growth factors and also play an important role in the response of the cell to growth factors either directly or indirectly through modulation of focal adhesions.

\section{References}

1. Bhaskar SN (ed): Periodontal ligament. In: Orban's Oral Histology and Embryology. Mosby Year Book, St. Louis, MO, pp203-238, 1990.

2. Grant D and Bernick S: The periodontium of ageing humans. J Periodontol 43: 660-667, 1972.

3. Severson JA, Moffett BC, KoKich V and Selipsky H: A histologic study of age changes in the adult human periodontal joint (ligament). J Periodontol 49: 189-200, 1978.

4. Moxam BJ and Evans IL: The effects of aging upon the connective tissues of the periodontal ligament. Connect Tissue Res 33: 31-35, 1995.

5. Polson AM, Meitner SW and Zander HA: Trauma and progression of marginal periodontitis in squirrel monkeys. III. Adaption of interproximal alveolar bone to repetitive injury. J Periodontal Res 11: 279-289, 1976.

6. Jin LJ and Cao CF: Clinical diagnosis of trauma from occlusion and its relation with severity of periodontitis. J Clin Periodontol 19: 92-97, 1992.

7. Shimizu N, Yamaguchi M, Goseki T, Ozawa Y, Saito K, Takiguchi H, Iwasawa $\mathrm{T}$ and Abiko $\mathrm{Y}$ : Cyclic-tension force stimulates interleukin-1B production by human periodontal ligament cells. J Periodontal Res 29: 328-333, 1994.

8. Yamaguchi M, Shimizu N, Goseki T, Shibata Y, Takiguchi H, Iwasawa $\mathrm{T}$ and Abiko $\mathrm{Y}$ : Effect of different magnitudes of tension force of prostaglandin E2 production by human periodontal ligament cells. Arch Oral Biol 39: 877-884, 1994.

9. Yamaguchi M, Shimizu N, Ozawa Y, Saito K, Miura S, Takiguchi $\mathrm{H}$ and Abiko $\mathrm{Y}$ : Effect of tension-force on plasminogen activator activity from human periodontal ligament cells. J Periodontal Res 32: 308-314, 1997.

10. Bosshardt DD and Schroeder HE: Initiation of acellular extrinsic fiber cementum on human teeth: a light- and electron-microscopy study. Cell Tissue Res 263: 311-324, 1991.

11. Bosshardt DD and Schroeder HE: Establishment of acellular extrinsic fiber cementum on human teeth: a light- and electronmicroscopy study. Cell Tissue Res 263: 325-336, 1991.

12. Yamamoto T and Hinrichsen KVS: The development of cellular cementum in rat molars, with special reference to the fiber arrangement. Anat Embryol (Berl) 188: 537-549, 1993.

13. Yamamoto $\mathrm{T}$, Domon $\mathrm{T}$, Takahashi $\mathrm{S}$ and Wakita M: Cellular cementogenesis in rat molars: the role of cementoblast in the deposition of intrinsic matrix fiber of cementum proper. Anat Embryol (Berl) 193: 495-500, 1996.

14. Nishimura K, Noguchi Y, Shigeyama Y, Naito M, Fukazawa E and Yamaoka A: An ultrastructural study comparing new gingival tissue attachment on chemically exposed fibrils and retained periodontal ligament. J Osaka Dent Univ 25: 63-75, 1991.
15. Takata T, Katauchi K, Akagawa Y and Nikai H: New connective tissue attachment formation on various biomaterials implanted in roots. Int J Oral Maxillofac Implants 9: 77-84, 1994.

16. Takata T, Katauchi K, Miyauchi K, Ogawa I, Akagawa Y and Nikai H: Periodontal tissue regeneration on the surface of synthetic hydroxyapatite implanted into root surface. J Periodontol 66: 125-130, 1995 .

17. Ralph WJ: Tensile behaviour of the periodontal ligament. J Periodontal Res 17: 423-426, 1982.

18. Mandel U, Dalgaard P and Viidik A: A biomechanical study of the human periodontal ligament. J Biomech 8: 637-645, 1986.

19. Komatsu K: In vitro mechanics of the periodontal ligament in impeded and unimpeded rat mandibular incisors. Arch Oral Biol 33: 783-791, 1988.

20. Chiba M, Yamane A, Ohshima S and Komatsu K: In vitro measurement of regional differences in the mechanical properties of the periodontal ligament in the rat mandibular incisor. Arch Oral Biol 35: 153-161, 1990.

21. Bruckner $P$ and van der Rest $M$ : Structure and function of cartilage collagens. Microsc Res Tech 28: 378-384, 1994.

22. Nimni M and Desmukh K: Differences in collagen metabolism between normal and osteoarthritic human articular cartilage. Science 181: 751-752, 1973

23. Benya PD, Padilla SR and Nimni ME: The progeny of rabbit articular chondrocytes synthesize collagens type I and III and type I trimer, but not type II. Verifications by cyanogen bromide peptide analysis. Biochemistry 16: 865-872, 1997.

24. Von der Mark K, Gauss V, von der Mark H and Müller P. Relationship between cell shape and type of collagen synthesized as chondrocytes lose their cartilage phenotype in culture. Nature 267: 531-532, 1977

25. Adam M and Deyl Z: Altered expression of collagen phenotype in osteoarthritis. Clin Chim Acta 133: 25-32, 1983.

26. Timpl R, Wiedemann H, van Delden V, Furthmayr H and Kuhn K: A network model for the organization of type IV collagen molecules in basement membranes. Eur J Biochem 120: 203-211, 1981

27. Kalluri R: Basement membranes: structure, assembly and role in tumour angiogenesis. Nat Rev Cancer 3: 422-433, 2003.

28. Carmeliet P and Jain RK: Angiogenesis in cancer and other diseases. Nature 407: 249-257, 2000.

29. Dessau W, Sasse J, Rimpl R, Jilek F and Vonder MK: Synthesis and extracellular deposition of fibronectin in chondrocyte cultures. Response to the removal of extracellular cartilage matrix. J Cell Biol 79: 342-355, 1978 .

30. Brownell AG, Bessem CC and Slavkin HC: Possible functions of mesenchyme cell-derived fibronectin during formation of basal lamina. Proc Natl Acad Sci USA 78: 3711-3715, 1981

31. Mosher DF: Fibronectin. Academic Press, San Diego, CA, 1989.

32. Engel J, Odermatt E, Engel A, Madri JA, Furthmay H, Rohde H and Timpl R: Shapes, domain organizations and flexibility of laminin and fibronectin, two multifunctional proteins of the extracellular matrix. J Mol Biol 150: 97-120, 1981.

33. Bumann A, Carvalho RS, Schwarzer CL and Yen EH: Collagen synthesis from human PDL cells following orthodontic tooth movement. Eur J Orthod 19: 29-37, 1997.

34. Carter DH and Sloan P: The fibrous architecture of the rat periodontal ligament in cryosections examined by scanning electron microscopy. Arch Oral Biol 39: 949-953, 1994.

35. Matsukawa F: Biochemical analysis of extracellular matrix in bovine periodontal ligament. J Osaka Dent Univ 28: 45-55, 1994.

36. Kuroiwa M, Chihara K and Higashi S: Electron microscopic studies on Sharpey's fibers in the alveolar bone of rat molars. Kaibogaku Zasshi 69: 776-782, 1994.

37. Furset R: Microradiographic and electron microscopic study of the cementum of human deciduous teeth. Acta Odontol Scand 25: 613-645, 1967.

38. Bercy P and Frank RM: Scanning electron microscopy of the surface of human cementum in various physiological and pathological conditions. J Biol Buccale 8: 353-373, 1980.

39. Proffit WR, Turvey TA and Phillips C: Orthognathic surgery: a hierarchy of stability. Int J Adult Orthodon Orthognath Surg 11: 191-204, 1996.

40. Yamasaki K, Hirota K, Yamasaki Y, Nonaka K and Nakata M: Investigation into the actual condition of patients with occlusal disharmony at the Pedodontic Clinic of Kyushu University. Cases of anterior cross-bite in the deciduous dentition. Shoni Shikagaku Zasshi 27: 522-528, 1989. 
41. Reynolds ES: The use of lead citrate at high $\mathrm{pH}$ as an electron opaque stain in electron microscopy. J Cell Biol 17: 208-212, 1963.

42. Parfitt GJ: Measurement of the physiological mobility of individual teeth in an axial direction. J Dent Res 39: 608-618, 1960.

43. Wills DJ, Picton DCA and Davies WIR: The intrusion of the tooth for different loading rates. J Biochem 11: 429-434, 1978.

44. Ralph WJ: The in vitro rupture of human periodontal ligament. J Biochem 13: 369-373, 1980.

45. Van Brocklin J and Ellis D: A study of the mechanical behavior of toe extensor tendons under applied stress. Arch Phys Med Rehabil 46: 369-373, 1965.

46. McElhaney JH: Dynamic response of bone and muscle tissue. J Appl Physiol 21: 1231-1236, 1966.

47. Fung Y: Biorheology of soft tissue. Biorheology 10: 139-155, 1973.

48. Embery G, Waddington R and Hall R: The ground substance of the periodontal ligament. In: The Periodontal Ligament Health and Disease. Berkovitz B, Moxam B and Newman H (eds). Mosby-Wolfe, London, pp83-106, 1995.

49. Mow VC, Mak AF, Lai WM, Rosenberg LC and Tang LH: Viscoelastic properties of proteoglycan subunits and aggregates in varying solution concentrations. J Biochem 17: 325-338, 1984.

50. Slatter JM and Picton DC: The effect of intrusive tooth mobility of noradrenaline injected locally in monkeys. J Periodontal Res 7: 144-150, 1972.

51. Walker T: A model of the periodontal vasculature in tooth support. J Biochem 13: 149-157, 1980.

52. Jonas IE and Riede UN: Reaction of oxytalan fibers in human periodontium to mechanical stress. A combined histochemical and morphometric analysis. J Histochem Cytochem 28: 211-213, 1980.

53. Howard PS, Kucich U, Taliwal R and Korostoff JM: Mechanical forces alter extracellular matrix synthesis by human periodontal ligament fibroblasts. J Periodontal Res 33: 500-508, 1998.
54. Marks MG, Doillon C and Silver FH: Effects of fibroblasts and basic fibroblast growth factor on facilitation of dermal wound healing by type I collagen matrices. J Biomed Mater Res 25: 4513-4520, 1991

55. Kanematsu A, Yamamoto S, Ozeki M, Noguchi T, Kanatani I, Ogawa $\mathrm{O}$ and Tabata Y: Collagenous matrices as release carries of exogenous growth factors. Biomaterials 25: 4513-4520, 2004.

56. Folkman J: Anti-angiogenesis: new concept for therapy of solid tumors. Ann Surg 175: 409-416, 1972.

57. Senger DR, Claffey KP, Benes JE, Perruzzi CA, Sergiou AP and Detmar M: Angiogenesis promoted by vascular endothelial growth factor: regulation through alpha1beta1 and alpha2beta1 integrins. Proc Natl Acad Sci USA 94: 13612-13617, 1997.

58. Paulsson M: Basement membrane proteins: structure, assembly, and cellular interactions (review). Crit Rev Biochem Mol Biol 27: 93-127, 1992.

59. Taniguchi T, Matsumoto T and Shindo H: Changes of serum levels of osteocalcin, alkaline phosphatase, IGF-I and IGF-binding protein-3 during fracture healing. Injury 34: 477-479, 2003.

60. Matsuda N, Lin WL, Kumar NM, Cho MI and Genco RJ: Mitogenic, chemotactic, and synthetic responses of rat periodontal ligament fibroblastic cells to polypeptide growth factors in vitro. J Periodontol 63: 515-525, 1992.

61. Ingber DE: Tensegrity: the architectural basis of cellular mechanotransduction. Annu Rev Physiol 59: 575-599, 1997.

62. Charlton WP, Coslett-Charlton LM and Ciccotti MG: Correlation of estradiol in pregnancy and anterior cruciate ligament laxity. Clin Orthop 387: 165-170, 2001.

63. Lee CY, Smith CL, Zhang X, Hsu HC, Wang DY and Luo ZP Tensile forces attenuate estrogen-stimulated collagen synthesis in the ACL. Biochem Biophys Res Commun 317: 1221-1225, 2004.

64. Hynes RO: Integrins: versatility, modulation, and signaling in cell adhesion. Cell 69: 11-25, 1992. 